\title{
Laparoscopic and open repair for perforated duodenal ulcer: single-center experience
}

\author{
Suren Agho Stepanyan, Areg Artak Petrosyan, Hayk Hovhannes Safaryan, Hayk Henrik Yeghiazaryan, \\ Andranik Yuri Aleksanyan, Vahe Mkrtich Hakobyan, Karen Tigran Papazyan, Mkrtich Hamlet Mkrtchyan \\ Department of Surgery 1, Yerevan State Medical University, Yerevan, Armenia
}

Videosurgery Miniinv 2019; 14 (1): 60-69

DOI: https://doi.org/10.5114/wiitm.2018.76281

\begin{abstract}
Introduction: Perforation is a dangerous complication of peptic ulcer disease and requires emergency surgical treatment. In recent decades laparoscopic repair of duodenal perforation has been widely used in emergency abdominal surgery.

Aim: To analyze laparoscopic and open surgical treatment of 120 consecutive patients with perforated duodenal ulcer. Material and methods: The study included a group of 120 consecutive patients, operated on for perforated duodenal ulcer in a single institution. Laparoscopic or open repair with or without an omental patch was performed. The value of the Boey score was investigated in predicting the outcomes of treatment in the entire study group.

Results: In 61 (50.8\%) cases open repair was performed, in 56 (46.7\%) cases laparoscopic repair, and in 3 (2.5\%) cases conversion was performed. In the laparoscopy group the mean hospital stay was 5 days (range: 3-14), in the open group 11.7 days (range: 6-63), and in the conversion group 9.3 days (8-10) ( $p<0.001)$. There was a significant difference between characteristics of patients in the laparoscopic groups: in the second period of laparoscopic procedures (2014-2017) the duration of the operation was significantly shorter and the number of postoperative complications was significantly lower than in the initial study group (2010-2013).

Conclusions: The laparoscopic approach is an effective method for treatment of perforated duodenal ulcer in selected cases. A number of 20-25 cases for the surgeon operating with the laparoscopic method is sufficient to achieve an acceptable level of expertise. More prospective randomized studies are needed to evaluate the effectiveness of laparoscopic repair of perforated duodenal ulcer.
\end{abstract}

Key words: laparoscopic surgery, peptic ulcer, peptic ulcer perforation.

\section{Introduction}

Perforation is a life-threatening complication of peptic ulcer disease (PUD) and requires immediate surgical intervention in most cases [1].

Despite the dramatic decrease in the incidence of PUD, the relative percentage of perforated ulcers remains stable $[2,3]$. Perforation occurs in $2-10 \%$ of cases of PUD with a high risk of mortality, especially among the elderly $[4,5]$. The mortality rate of PUD per- forations is in the range $10-40 \%[4,6]$. The cause of $70 \%$ of deaths in patients with PUD is perforation [7]; in-hospital mortality rates vary from $5 \%$ to $24 \%$ [8-11].

Simple closure with or without an omental patch is the most common and accepted emergency procedure in many centers $[12,13]$.

In recent decades laparoscopic repair of duodenal perforation has been widely used in many clinics in the USA, Western Europe and Asia, with favorable results $[1,12,14-18]$. 
Nathanson et al. (1990) reported the first successful laparoscopic suture repair for perforated peptic ulcer [19]. The first laparoscopic sutureless repair for perforated duodenal ulcer was performed by Mouret et al. They used fibrin glue and covered the perforation with an omental patch [20]. The concept of sutured closure is the laparoscopic counterpart to the open technique, whereas non-sutured repair does not require laparoscopic suturing skills and has the advantage of shorter operative time [21-23].

Simple closure of the perforation with an omental patch is a technically easy, reliable and preferable method [24-26]. Laparoscopic repair of perforated duodenal ulcer is superior to conventional open repair in terms of reduced pain, shorter hospital stay, better cosmetics and wound healing, and lower incidence of incisional hernias [16, 27]. Some authors adhere to strict selection of patients with perforated peptic ulcer for laparoscopy and use it for low-risk patients [5]. Others adhere to a "laparoscopy-first" policy in the treatment of perforated peptic ulcer [12]. Laparoscopic repair of perforated duodenal ulcer has been used for a long time, but still many questions are controversial.

\section{Aim}

The aim of this study was to analyze laparoscopic and open surgical treatment of 120 consecutive patients with perforated duodenal ulcer.

\section{Material and methods}

The study included a group of 120 consecutive patients, 108 (90\%) males and 12 (10\%) females, treated in a single institution. The average age of patients was 46.4 (range: 18-89) years. After the diagnosis of a perforated ulcer the treatment was stratified according to the severity of the disease. The Boey score, used for evaluation of the severity of the disease, is based on the available information of the following three criteria: shock at admission (systolic blood pressure $<90 \mathrm{~mm} \mathrm{Hg}$ ), severe medical illness (ASA III-V), and delayed presentation (duration of symptoms $>24 \mathrm{~h}$ ). For this scoring system, the patient is given one point for each positive criterion, with possible scores of $0-3$. Patients with a Boey score of 0-2 were subjected to laparoscopy or laparotomy at the discretion of the consulting surgeon. Patients with a Boey score of 3 were considered for

Table I. Characteristics of patients according to surgical approach

\begin{tabular}{|c|c|c|c|c|}
\hline Characteristic & $\begin{array}{l}\text { Laparoscopy group } \\
\quad(n=56,46.7 \%)\end{array}$ & $\begin{array}{l}\text { Laparotomy group } \\
\quad(n=61,50.8 \%)\end{array}$ & $\begin{array}{l}\text { Conversion group } \\
(n=3,2.5 \%)\end{array}$ & $P$-value \\
\hline Male & $54(96.4 \%)$ & $51(83.6 \%)$ & $3(100 \%)$ & 0.058564 \\
\hline Age, median (range) [years] & $40.3(18-63)$ & $51.9(19-89)$ & $48.7(48-50)$ & 0.000448 \\
\hline $\begin{array}{l}\text { Preoperative delay, } \\
\text { median (range) }[\mathrm{h}]\end{array}$ & $4.2(0.4-12)$ & $23.8(0.5-240)$ & $3.3(2-5)$ & 0.003396 \\
\hline \multicolumn{4}{|l|}{ ASA class, $n(\%):$} & \multirow[t]{6}{*}{0.00213} \\
\hline I & $5(8.9)$ & $1(1.6)$ & 0 & \\
\hline$\|$ & $23(41.1)$ & $9(14.8)$ & $1(33.3)$ & \\
\hline III & $25(44.6)$ & $30(49.2)$ & $2(66.7)$ & \\
\hline IV & $3(5.4)$ & $18(29.5)$ & 0 & \\
\hline V & 0 & $3(4.9)$ & 0 & \\
\hline \multicolumn{4}{|l|}{ Boey score, $n(\%)$ : } & \multirow[t]{5}{*}{$<0.001$} \\
\hline 0 & $26(46.4)$ & $8(13.1)$ & $1(33.3)$ & \\
\hline 1 & $26(46.4)$ & $24(39.3)$ & $1(33.3)$ & \\
\hline 2 & $4(7.2)$ & $22(36.1)$ & $1(33.3)$ & \\
\hline 3 & 0 & 7 (11.5) & 0 & \\
\hline $\begin{array}{l}\text { Duration of operation, median } \\
\text { (range) [min] }\end{array}$ & $94(45-140)$ & $126(60-180)$ & $173(150-210)$ & $<0.001$ \\
\hline
\end{tabular}

ASA - American Society of Anesthesiologists. 
laparotomy. The characteristics of the patients are presented in Table I.

Preoperative workup included plain X-ray of abdomen and chest, computed tomography (CT) of abdomen, and esophagogastroduodenoscopy in selected cases. Two scoring systems - American Society of Anesthesiologists (ASA) class and Boey score - were used for evaluation of the patients' condition.

Open procedures were performed by upper median laparotomy. The perforation site was repaired with Vicryl 3-0 (Johnson \& Johnson International, European Logistics Centre, Diegem, Belgium) or PDS 3-0 (Johnson \& Johnson International, European Logistics Centre, Diegem, Belgium) or Caprofil 3-0 (Ethicon, Division of Johnson \& Johnson Medical Limited, Livingston, Scotland) stitched by a round body needle tied over an omental patch or without it.

In all the laparoscopic procedures we used the Lloyd-Davies position with reverse Trendelenburg tilt. All the procedures were performed by surgeons experienced in laparoscopy and intracorporeal suturing. The surgeon stood between the patient's legs, and the camera operator stood at the patient's left side. Pneumoperitoneum was created by a Veress needle or with open placement of the first trocar (pressure of 12-14 mm Hg). The first $10 \mathrm{~mm}$ trocar for the telescope was placed in the infraumbilical region. A $45^{\circ}$ telescope was used for all the procedures. After confirmation of the diagnosis, 3 additional working trocars were placed: a $5 \mathrm{~mm}$ trocar

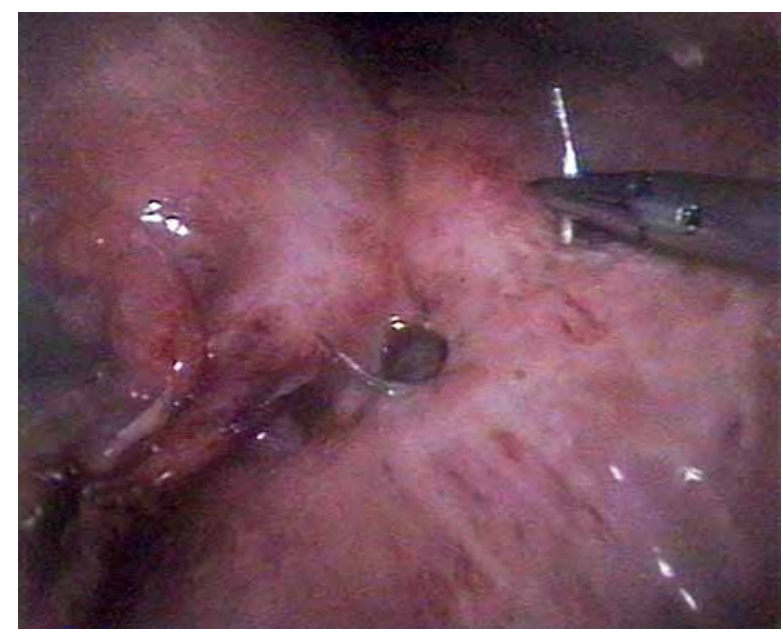

Photo 1. Laparoscopic repair. Stitching of perforation in the right subcostal region at the anterior axillary line, a $5 \mathrm{~mm}$ trocar in the left subcostal region at the midclavicular line and a $10 \mathrm{~mm}$ trocar in the right subcostal region at the midclavicular line for the fan liver retractor (Medtronic, Norwalk, Connecticut, USA). After checking the abdominal cavity and identification of the perforation site, the latter was repaired with a PDS 3-0 or Caprofil 3-0 stitch by a round body needle tied over an omental patch or without it (Photos 1, 2). During laparoscopic repair we used intracorporeal or extracorporeal knotting techniques.

Procedures were completed with leak testing. After repair of the perforation site, the abdominal cavity was irrigated with 4-6 liters of normal saline solution. The abdominal cavity was drained routinely. The subhepatic tube, placed on the stitched ulcer, was removed in 3-4 postoperative days.

In the postoperative period all the patients received intravenous fluids, broad-spectrum antibiotics, intravenous proton pump inhibitors (PPI), and analgesics, and underwent gastric decompression by a nasogastric tube for 1-2 days. A liquid diet was prescribed to the patients on the second day after the operation, which gradually progressed to a full diet with restoration of bowel movements. Upon being-discharged, the patients received oral proton pump inhibitor (PPI) medication for 8 weeks.

The study was approved by the Ethics Committee of Yerevan State Medical University. This study is the first and largest one in the Republic of Armenia.

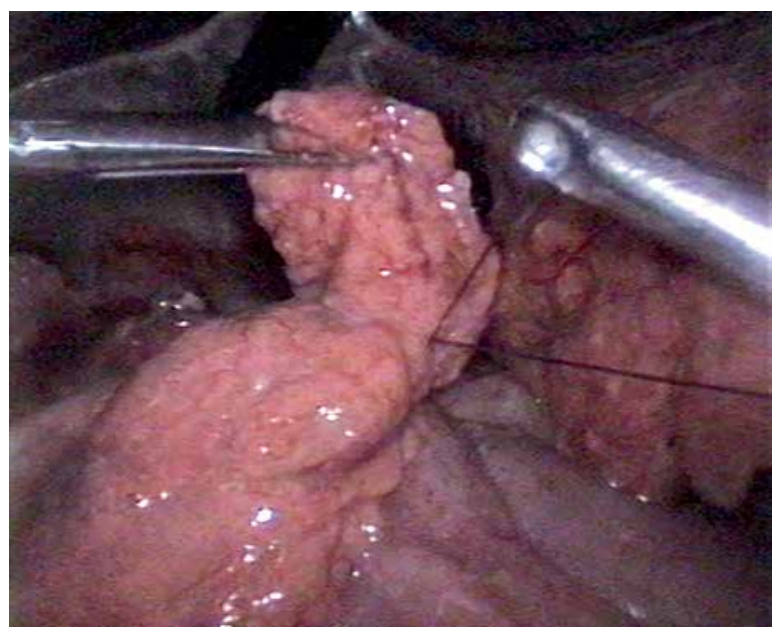

Photo 2. Laparoscopic repair with omental patch. The process of extracorporeal knotting technique 


\section{Statistical analysis}

The data were collected, entered into a database, and statistical analysis was performed by MS Excel 2007 (Microsoft Corp., USA). For calculation of the $p$-value, the ANOVA test ( $F$-test) and $\chi^{2}$ test (chisquared test) were used. A $p$-value of less than 0.05 was considered statistically significant. During calculation of the $p$-value the rows and columns having only results of 0 were excluded.

\section{Results}

In this study we retrospectively reviewed 120 consecutive patients operated on for perforated duodenal ulcer during the last 8 years (April 2010 to December 2017). The results of the study reveal that in $37(30.8 \%)$ patients perforation was the first manifestation of PUD. Nonsteroidal anti-inflammatory drugs (NSAIDs) were used in the past by $16(13.3 \%)$ patients. There were 92 (76.7\%) smokers and 29 (24.2\%) alcohol abusers. In the laparoscopy group $11(19.6 \%)$ patients had abdominal operations in the past: 10 patients had open appendectomy and 1 patient had inguinal open hernioplasty. In the open group 17 (27.9\%) patients had laparotomy for various reasons in the past: perforated duodenal ulcer (3 cases), appendicitis (8 cases), appendicitis with abdominal hernia (2 cases), cholecystitis (1 case), gynecological (1 case), penetrated injury of abdomen (2 cases). In the conversion group no patient had abdominal procedures in the past.

The diagnosis was based on clinical (abdominal pain, muscle guarding, rebound tenderness), endoscopic and radiological signs (pneumoperitoneum). The X-ray examination revealed pneumoperitoneum in $66(55 \%)$ cases, in $14(11.7 \%)$ cases it was revealed on double $\mathrm{X}$-ray examination, and in $40(33.3 \%)$ cases $X$-ray results were negative. Computed tomography scan performed in 46 cases revealed free air and fluid in the abdominal cavity.

All the patients had symptoms of peritonitis. In $13(10.8 \%)$ cases there was localized peritonitis in the upper abdomen, in 20 (16.7\%) generalized peritonitis, and in $87(72.5 \%)$ generalized peritonitis with frank pus and pyogenic membranes all over the abdomen. Only 75 (62.5\%) patients were admitted to hospital during the first $6 \mathrm{~h}$ from the moment of the perforation. In the laparotomy group $18(29.5 \%)$ patients had symptoms of septic shock, $16(26.2 \%)$ patients had severe cardiovascular and pulmonary diseases, and 22 (36.1\%) patients were admitted to hospital later than $24 \mathrm{~h}$ from the onset of symptoms of perforation.

The outcomes of the treatment according to surgical approach are presented in Table II.

In the laparoscopy group simple closure was performed in $16(28.6 \%)$ patients, and omental patch repair was performed in 40 (71.4\%) patients.

The laparoscopic repair of perforated peptic ulcer was performed by 3 surgeons.

In the laparotomy group 9 patients had simple repair (14.8\%), 49 patients had omental patch repair (80.3\%), and 3 patients had ulcer excision and repair (4.9\%).

Three cases were converted to an open procedure due to difficulty of identification of the perforation site (1 patient) and challenging repair (2 patients). In all $3(100 \%)$ cases omental patch repair was performed.

Patients who underwent laparoscopic repair were younger, the duration of symptoms was shorter, and they were mainly ASA class I, II and III. The majority of the cases with ASA class III and IV were in the open group.

There was one fatal outcome in the laparoscopy group (cardiovascular incident, Boey score 1 ) and 17 in the laparotomy group (6 patients with a Boey score of 3, 10 patients with a Boey score of 2, and 1 patient with a Boey score of 1). In the laparotomy group the causes of death were cardiovascular complications in 9 cases, pulmonary complications in 5 cases, and postoperative complications in 3 cases.

Leak from the suture line developed in 6 cases ( 3 in the laparoscopy group and 3 in the laparotomy group). In all cases the leak was revealed by drain control. All 3 cases in the laparoscopy group were managed conservatively by nasogastric tube aspiration and subhepatic drainage for 7 days. None of the patients required reoperation. No residual intraperitoneal abscess was detected in the laparoscopy group.

In the open group 1 patient with suture leak was managed conservatively, and 2 cases required reoperation. In 2 cases of reoperation feeding jejunostomy was performed. One patient died after the reoperation due to suture leak as a result of cardiovascular complications.

For this analysis two periods (2010-2013 and 2014-2017) after implementation of the laparoscopic method were compared. During the first period 26 procedures were performed, while during the second period there were 30 procedures (Table III). 
There was a significant difference in the duration of the operation, postoperative complications and mortality between groups. All the cases of suture leak occurred during the first period.

In comparison of characteristics and outcomes of patients with a Boey score of 0 and 1 in the laparoscopy group no statistically significant difference was revealed for duration of the operation, postoperative complications, duration of hospitalization or mortality (Table IV). Duration of operation, number of postoperative complications, duration of hospitalization and mortality rate were shorter/lower in cases with a Boey score of 0 than in those with a Boey score of 1. Analysis of higher Boey scores for laparoscopically treated patients was impossible due to the low numbers of patients.

Due to the policy of patients' allocation into treatment groups, only the group with a Boey of score 1 underwent comparable numbers of laparoscopic and open surgical procedures. There was a statistically significant difference between the groups for two characteristics of patients with a Boey score of 1: duration of operation and length of hospitalization were shorter in the laparoscopy group (Table V). There was no difference in morbidity or mortality between open and laparoscopic groups with a Boey score of 1 .

\section{Discussion}

Proton pump inhibitors and $H$. pylori eradication therapy have significantly decreased the rate of PUD complications, but perforation of duodenal ulcer is still quite frequent in developing countries [28, 29].

Guidelines for management of intra-abdominal infections of the World Journal of Emergency Surgery (2013) note that surgery is the treatment of choice for perforated peptic ulcer [30]. The laparoscopic approach for perforated peptic ulcer has significant advantages. It allows better visualization, is less traumatic and allows quick recovery after the

Table II. Outcomes of treatment according to surgical approach

\begin{tabular}{|c|c|c|c|c|}
\hline Characteristic & $\begin{array}{l}\text { Laparoscopy group } \\
\quad(n=56,46.7 \%)\end{array}$ & $\begin{array}{l}\text { Laparotomy group } \\
\qquad(n=61,50.8 \%)\end{array}$ & $\begin{array}{l}\text { Conversion group } \\
\quad(n=3,2.5 \%)\end{array}$ & $P$-value \\
\hline $\begin{array}{l}\text { Postoperative complications, } \\
\text { cases }\end{array}$ & $6(10.7 \%)$ & $27(44.3 \%)$ & 0 & 0.000147 \\
\hline $\begin{array}{l}\text { Without postoperative } \\
\text { complications, cases }\end{array}$ & $50(89.7 \%)$ & $34(55.7 \%)$ & $3(100 \%)$ & 0.000147 \\
\hline \multicolumn{4}{|c|}{ Complications according to Clavien-Dindo classification, $n(\%)$ : } & 0.0044 \\
\hline Grade I & 0 & $2(3.3)$ & 0 & \\
\hline Grade II & $2(3.6)$ & $5(8.2)$ & 0 & \\
\hline Grade IIIa & $3(5.4)$ & 0 & 0 & \\
\hline Grade IIIb & 0 & $2(3.3)$ & 0 & \\
\hline Grade IV & 0 & $1(1.6)$ & 0 & \\
\hline Grade V & $1(1.8)$ & $17(27.9)$ & 0 & \\
\hline Suture leak, $n(\%)$ & $3(5.4)$ & $3(4.9)$ & 0 & 0.916771 \\
\hline $\begin{array}{l}\text { Abdominal abscess, } \\
\text { peritonitis, } n(\%)\end{array}$ & 0 & $2(3.3)$ & 0 & 0.37396 \\
\hline Wound infection, $n$ (\%) & 0 & $4(6.6)$ & 0 & 0.135182 \\
\hline Pulmonary complications, $n$ (\%) & $3(5.4)$ & $14(23)$ & 0 & 0.018872 \\
\hline Bowel obstruction, $n(\%)$ & 0 & $1(1.6)$ & 0 & 0.614055 \\
\hline Other complications, $n(\%)$ & $1(1.8)$ & $18(29.5)$ & 0 & 0.000165 \\
\hline Reoperation, $n(\%)$ & 0 & $5(8.2)$ & 0 & 0.080205 \\
\hline $\begin{array}{l}\text { Length of hospital stay, median } \\
\text { (range) [days] }\end{array}$ & $5(3-14)$ & $9.8(6-31)$ & $9.3(8-10)$ & $<0.001$ \\
\hline Mortality, n (\%) & $1(1.8)$ & $17(27.9)$ & 0 & 0.000316 \\
\hline
\end{tabular}


Table III. Comparison of characteristics of patients and outcomes of treatment in laparoscopy groups

\begin{tabular}{|c|c|c|c|}
\hline \multirow[t]{2}{*}{ Characteristic } & \multicolumn{2}{|c|}{ Periods } & \multirow[t]{2}{*}{$P$-value } \\
\hline & $\begin{array}{c}2010-2013 \\
(n=26,46.4 \%)\end{array}$ & $\begin{array}{c}2014-2017 \\
(n=30,53.6 \%)\end{array}$ & \\
\hline Male & 26 & 28 & 0.18 \\
\hline Age, median (range) [years] & $39.7(21-59)$ & $40.9(18-63)$ & 0.7265 \\
\hline Preoperative delay, median (range) [h] & $3.7(0.4-10)$ & $4.7(0.5-12)$ & 0.2305 \\
\hline Previous abdominal operations & 5 & 6 & 0.9424 \\
\hline ASA class: & & & 0.514 \\
\hline 1 & 1 & 4 & \\
\hline 1 & 10 & 13 & \\
\hline III & 13 & 12 & \\
\hline IV & 2 & 1 & \\
\hline V & 0 & 0 & \\
\hline Boey score: & & & 0.4745 \\
\hline 0 & 11 & 15 & \\
\hline 1 & 14 & 12 & \\
\hline 2 & 1 & 3 & \\
\hline 3 & 0 & 0 & \\
\hline Duration of operation, median (range) [min] & $101(45-140)$ & $89(50-130)$ & 0.043 \\
\hline Postoperative complications & 5 & 1 & 0.054 \\
\hline Complications according to Clavien-Dindo classification: & & & 0.301 \\
\hline Grade I & 0 & 0 & \\
\hline Grade $\|$ & 1 & 1 & \\
\hline Grade IIIa & 3 & 0 & \\
\hline Grade IIIb & 0 & 0 & \\
\hline Grade IV & 0 & 0 & \\
\hline Grade V & 1 & 0 & \\
\hline Suture leak & 3 & 0 & 0.0558 \\
\hline Pulmonary complications & 2 & 1 & 0.47 \\
\hline Other complications (urinary retention) & 1 & 0 & 0.0278 \\
\hline Length of hospital stay, median (range) [days] & $5.4(3-14)$ & $4.7(3-9)$ & 0.2989 \\
\hline Mortality & 1 & 0 & 0.0278 \\
\hline
\end{tabular}

operation [12, 31]. Bertleff and Lange conclude that laparoscopic repair of perforated peptic ulcer should be the treatment of choice [4].

Patients' selection for laparoscopic repair is still disputable. There are no firm criteria for patient selection for the laparoscopic approach [9, 12]. Guadagni et al. suggest reserving laparotomy for highrisk patients who had septic shock on admission, severe cardiopulmonary comorbidities, or a history of upper abdominal surgery [12, 16, 22]. In some surgical departments of western Denmark the laparoscopic operation for perforated peptic ulcer was performed without any selection criteria with low mortality but higher risk of re-perforation [32].

In our study the Boey score was used for patients' selection. Preoperative patients' selection resulted in 
Table IV. Characteristics of patients with Boey score of 0 and 1 in laparoscopy group

\begin{tabular}{|c|c|c|c|}
\hline Characteristic & $\begin{array}{c}\text { Boey } 0 \\
(n=26,50 \%)\end{array}$ & $\begin{array}{c}\text { Boey } 1 \\
(n=26,50 \%)\end{array}$ & $P$-value \\
\hline Male & 26 & 25 & 0.313 \\
\hline Age, median (range) [years] & $39.3(18-63)$ & $40.9(21-60)$ & 0.6735 \\
\hline Preoperative delay, median (range) [h] & $3.6(0.4-12)$ & $4.6(0.5-12)$ & 0.2865 \\
\hline Systolic blood pressure $<90 \mathrm{~mm} \mathrm{Hg}$ & 0 & 2 & 0.149 \\
\hline Comorbid diseases & 2 & 7 & 0.067 \\
\hline Previous abdominal operations & 6 & 3 & 0.271 \\
\hline ASA class: & & & $<0.001$ \\
\hline I & 5 & 0 & \\
\hline$\|$ & 21 & 2 & \\
\hline III & 0 & 21 & \\
\hline IV & 0 & 3 & \\
\hline V & 0 & 0 & \\
\hline Duration of operation, median (range) [min] & $90(45-130)$ & $100(50-140)$ & 0.16 \\
\hline Postoperative complications & 2 & 4 & 0.385 \\
\hline Complications according to Clavien-Dindo classification: & & & 0.687 \\
\hline Grade I & 0 & 0 & \\
\hline Grade II & 1 & 1 & \\
\hline Grade IIla & 1 & 2 & \\
\hline Grade IIIb & 0 & 0 & \\
\hline Grade IV & 0 & 0 & \\
\hline Grade V & 0 & 1 & \\
\hline Suture leak & 1 & 2 & 0.552 \\
\hline Pulmonary complications & 1 & 2 & 0.552 \\
\hline Other complications & 1 & 0 & 0.313 \\
\hline Length of hospital stay, median (range) [days] & $4.7(3-12)$ & $5.2(3-14)$ & 0.49 \\
\hline Mortality & 0 & 1 & 0.313 \\
\hline
\end{tabular}

acceptable results in the laparoscopy group: young patients with duration of symptoms up to $12 \mathrm{~h}$, ASA class I, II and III, without severe cardiopulmonary comorbidities or septic shock on admission. Ten different scoring systems were suggested for patients with perforated peptic ulcer, and four of them are specific for this group (the Boey score, the Hacettepe score, the Jabalpur score and the Peptic Ulcer Perforation (PULP) score) [33]. Many authors note that the Boey score is easier to use, specific for perforated peptic ulcer and provides valid prediction of morbidity and mortality. The Boey score is widely used in many clinics [4, 13, 33-35]. A Boey score of
0 or 1 predicts favorable outcomes for laparoscopic and open interventions for perforated peptic ulcer, and a score of 3 is considered a contraindication for laparoscopic repair of perforated peptic ulcer [4, 22].

Based on the Boey score we excluded all patients with cardiovascular and respiratory comorbid diseases and severe peritonitis (Boey score 3) from the laparoscopy group. Fifty-four patients (91.5\%) had a Boey score of 0 or 1 in the laparoscopy and conversion groups, 32 (52.4\%) patients in the open group. In the laparoscopic group the results between Boey score 0 and Boey score 1 patients did not differ significantly. 
Table V. Characteristics of patients with Boey score of 1 in open and laparoscopy groups

\begin{tabular}{|c|c|c|c|}
\hline Characteristic & $\begin{array}{l}\text { Laparoscopy and } \\
\text { conversion groups } \\
(n=27,52.9 \%)\end{array}$ & $\begin{array}{l}\text { Laparotomy group } \\
\quad(n=24,47.1 \%)\end{array}$ & $P$-value \\
\hline Male & 26 & 20 & 0.120 \\
\hline Age, median (range) [years] & $41.2(21-60)$ & $48.7(23-87)$ & 0.082 \\
\hline Preoperative delay, median (range) [h] & $4.5(0.5-12)$ & $5.9(0.5-24)$ & 0.27 \\
\hline Systolic blood pressure $<90 \mathrm{~mm} \mathrm{Hg}$ & 2 & 1 & 0.623 \\
\hline Comorbid diseases & 7 & 4 & 0.422 \\
\hline Previous abdominal operations & 3 & 8 & 0.054 \\
\hline ASA class: & & & 0.411 \\
\hline I & 0 & 0 & \\
\hline II & 2 & 2 & \\
\hline III & 22 & 16 & \\
\hline IV & 3 & 6 & \\
\hline $\mathrm{V}$ & 0 & 0 & \\
\hline Duration of operation, median (range) [min] & $100(50-140)$ & $132(90-180)$ & 0.003 \\
\hline Postoperative complications & 4 & 5 & 0.574 \\
\hline Complications according to Clavien-Dindo classification: & & & 0.268 \\
\hline Grade I & 0 & 1 & \\
\hline Grade II & 1 & 3 & \\
\hline Grade IIIa & 2 & 0 & \\
\hline Grade IIIb & 0 & 0 & \\
\hline Grade IV & 0 & 0 & \\
\hline Grade V & 1 & 1 & \\
\hline Suture leak & 2 & 0 & 0.174 \\
\hline Wound infection & 0 & 1 & 0.284 \\
\hline Pulmonary complications & 2 & 2 & 0.902 \\
\hline Other complications & 0 & 1 & 0.284 \\
\hline Length of hospital stay, median (range) [days] & $5.3(3-14)$ & $9.9(7-20)$ & $<0.001$ \\
\hline Mortality & 1 & 1 & 0.932 \\
\hline
\end{tabular}

Conversion was mainly associated with technical difficulties which were impossible to predict before the operation. The conversion rate is still high in many clinics; in some studies it reaches $28.5-30.4 \%$ $[4,12-14,16]$. In 2 cases of conversion in our study there were difficulties in suturing. Intraoperatively suture leak was detected, and the procedure was converted to open.

Suture leak remains the most dangerous surgical complication after perforated peptic ulcer repair. In some studies it has a high incidence $(7-9 \%)[9,22]$.
In our study in 4 cases suture leak was detected on the third, in 2 cases on the fourth postoperative day. In the open group the causes of suture leak were significant inflammation and infiltration in the pyloroduodenal region. In the laparoscopy group all 3 cases of suture leak and 2 cases of conversion occurred in the first period of laparoscopic procedures.

In many studies the average duration of surgery of laparoscopic repair was 65-95 min (range: 25$190 \mathrm{~min}$ [4, 9, 12, 14, 22, 23]. In some studies duration of the operation was significantly longer in the 
laparoscopy group than in the open group [22, 23] In our study the average duration of the operation was significantly shorter in the laparoscopy group than in the open group. Moreover, it significantly decreased during the second period of laparoscopic procedures. In the laparoscopy group the average duration of the operation was significantly shorter in the extracorporeal $(n=29)$ than in the intracorporeal $(n=27)$ knotting group (87 (45-120) min vs. 105 (60-140) min, respectively; $p=0.00879)$.

The mortality rate was high in the open group due to severe comorbidities. This is the result of the allocation of severely ill patients to the open group. When comparing open and laparoscopic procedures for patients with a Boey score of 1 , the morbidity and mortality were similar.

Authors' opinions about advantages of laparoscopic repair of perforated peptic ulcer vary [36, 37]. In one study the authors found no statistically significant differences in morbidity and mortality between open and laparoscopic repair [9]. Some studies confirm that the use of laparoscopic repair for the treatment of perforated peptic ulcers remains controversial due to the concerns related to a longer operation time, leak and the high rate of reoperation [21], which was not observed in our study. Other studies on laparoscopic repair of perforated peptic ulcer have shown that this method is more favorable than the open repair method as it involves less analgesic therapy, has a shorter hospital stay, a lower rate of wound infection, a lower mortality rate and earlier return to work $[22,38,39]$. The limiting factor in laparoscopic repair of perforated peptic ulcer is the lack of availability of expertise and competency of the surgeon $[28,40]$.

It was revealed in a group of patients with a Boey score of 1 that the duration of the operation and hospitalization was significantly shorter in laparoscopic than in open procedures. In the laparotomy group wound infection occurred in more cases than after laparoscopic procedures. Comparison of two periods of laparoscopic procedures showed better results due to the gaining of experience in laparoscopic repair of perforated ulcer. Postoperative surgical complications occurred mostly during the learning curve.

Our study results show that laparoscopic repair for perforated duodenal ulcer is feasible with acceptable mortality and morbidity rates. Patients' selection and surgeons' experience are crucial for favorable outcomes of laparoscopic cases.
Limitations of our study are that it was retrospective and non-randomized. Patients for the laparoscopy group were selected with a Boey score of 0-1, whereas patients for the laparotomy group mainly had a Boey score of $1-3$, which might have affected the outcomes.

\section{Conclusions}

The laparoscopic approach is an effective method for treatment of perforated duodenal ulcer in selected cases. A number of 20-25 cases for the surgeon operating with the laparoscopic method is sufficient to achieve an acceptable level of expertise. More prospective randomized studies are needed to evaluate the effectiveness of laparoscopic repair of perforated duodenal ulcer.

\section{Acknowledgments}

The authors would like to thank Dr. Davit Sargsyan (Consultant general surgeon from Hamad Medical Corporation) for reviewing this paper and providing valuable input.

This paper has been supported by the European Surgical Publication and Research Initiative (ESPRIT) of the European Society of Surgery.

\section{Conflict of interest}

The authors declare no conflict of interest.

\section{References}

1. Zimmermann M, Wellnitz T, Laubert T, et al. Gastric and duodenal perforations: what is the role of laparoscopic surgery? Zentralbl Chir 2014; 139: 72-8.

2. Thorsen K, Soreide J.A, Kvaloy JT, et al. Epidemiology of perforated peptic ulcer: age- and gender-adjusted analysis of incidence and mortality. World J Gastroenterol 2013; 19: 347-54.

3. Sarosi GA, Jaiswal KR, Nwariaku FE, et al. Surgical therapy of peptic ulcers in the 21st century: more common than you think. Am J Surg 2005; 190: 775-9.

4. Bertleff MJ, Lange JF. Perforated peptic ulcer disease: a review of history and treatment. Dig Surg 2010; 27: 161-9.

5. Siu WT, Leong HT, Li MK. Single stitch laparoscopic omental patch repair of perforated peptic ulcer. J R Coll Surg Edinb 1997; 42: 2-4.

6. Møller MH, Adamsen S, Wojdemann M, et al. Perforated peptic ulcer: how to improve outcome? Scand I Gastroenterol 2009; 44: 15-22.

7. Kashiwagi H. Ulcer and gastritis. Endoscopy 2007; 39: 101-5.

8. Svanes C. Trends in perforated peptic ulcer: incidence, etiology, treatment, and prognosis. World J Surg 2000; 24: 277-83. 
9. Thorsen K, Glomsaker T.B, von Meer A, et al. Trends in diagnosis and surgical management of patients with perforated peptic ulcer. J Gastrointest Surg 2011; 15: 1329-35.

10. Imhof M, Epstein S, Ohmann C, et al. Duration of survival after peptic ulcer perforation. World J Surg 2008; 32: 408-12.

11. Bonin EA, Moran E, Gostout CJ, et al. Natural orifice transluminal endoscopic surgery for patients with perforated peptic ulcer. Surg Endosc 2012; 26: 1534-8.

12. Guadagni S, Cengeli I, Galatioto C, et al. Laparoscopic repair of perforated peptic ulcer: single-center results. Surg Endosc 2014; 28: 2302-8.

13. Mouly C, Chati R, Scotté M, et al. Therapeutic management of perforated gastro-duodenal ulcer: literature review. J Visc Surg 2013; 150: 333-40.

14. Aljohari H, Althani $\mathrm{H}$, Elmabrok G, et al. Outcome of laparoscopic repair of perforated duodenal ulcers. Singapore Med J 2013, 54: 216-9.

15. Palanivelu C, Jani K, Senthilnathan P. Laparoscopic management of duodenal ulcer perforation: is it advantageous? Indian J Gastroenterol 2007; 26: 64-6.

16. Kim JH, Chin HM, Bae YJ, et al. Risk factors associated with conversion of laparoscopic simple closure in perforated duodenal ulcer. Int J Surg 2015; 15: 40-4.

17. Søreide K, Thorsen K, Søreide JA. Strategies to improve the outcome of emergency surgery for perforated peptic ulcer. Br J Surg 2014; 101: 51-64.

18. Byrge N, Barton RG, Enniss TM, et al. Laparoscopic versus open repair of perforated gastroduodenal ulcer: a National Surgical Quality Improvement Program analysis. Am J Surg 2013; 206: 957-63.

19. Nathanson LK, Easter DW, Cuschieri A. Laparoscopic repair/ peritoneal toilet of perforated duodenal ulcer. Surg Endosc 1990; 4: 232-3.

20. Mouret P, Francois Y, Vignal J, et al. Laparoscopic treatment of perforated peptic ulcer. Br J Surg 1990; 77: 1006.

21. Law WY, Leung KL, Zhu XL, et al. Laparoscopic repair of perforated peptic ulcer. Br J Surg 1995; 82: 814-6.

22. Lunevicius R, Morkevicius M. Comparison of laparoscopic versus open repair for perforated duodenal ulcers. Surg Endosc 2005; 19: 1565-71.

23. Minutolo V, Gagliano G, Rinzivillo C, et al. Laparoscopic surgical treatment of perforated duodenal ulcer. Chir Ital 2009; 61: 309-13.

24. Bornman PC, Theodorou NA, Jeffery PC. Simple closure of perforated duodenal ulcer: a prospective evaluation of a conservative management policy. Br J Surg 1990; 77: 73-5.

25. Turner WT, Thompson WM, Thal ER. Perforated gastric ulcers. A plea for management by simple closure. Arch Surg 1988; 123 : 960-4.

26. Collier D, Pain JA. Perforated peptic ulcers. J R Coll Surg Edinb 1985; 30: 26-9.

27. Mitura K, Skolimowska-Rzewuska M, Garnysz K. Outcomes of bridging versus mesh augmentation in laparoscopic repair of small and medium midline ventral hernias. Surg Endosc 2017; 31: $382-8$.

28. Siu WT, Leong HT, Law BK, et al. Laparoscopic repair for perforated peptic ulcer. Ann Surg 2002; 235: 313-9.
29. Durai R, Razvi A, Uzkalnis A, et al. Duodenal ulcer perforation: a district hospital experience. Acta Chir Belg 2011; 111: 23-5.

30. Sartelli M, Viale P, Catena F, et al. 2013 WSES guidelines for management of intra-abdominal infections. World J Emerg Surg 2013; 8: 3 .

31. Arnaud JP, Tuech JJ, Bergamaschi R, et al. Laparoscopic suture closure of perforated duodenal peptic ulcer. Surg Laparosc Endosc Percutan Tech 2002; 12: 145-7.

32. Sommer T, Elbroend H, Friis-Andersen H. Laparoscopic repair of perforated ulcer in Western Denmark - a retrospective study. Scand J Surg 2010; 99: 119-21.

33. Thorsen K, Søreide JA, Søreide K. Scoring systems for outcome prediction in patients with perforated peptic ulcer. Scand J Trauma Resusc Emerg Med 2013; 21: 25.

34. Lohsiriwat V, Prapasrivorakul S, Lohsiriwat D. Perforated peptic ulcer: clinical presentation, surgical outcomes, and the accuracy of the Boey scoring system in predicting postoperative morbidity and mortality. World J Surg 2009; 33: 80-5.

35. Boey J, Choi SK, Poon A, et al. Risk stratification in perforated duodenal ulcers. A prospective validation of predictive factors. Ann Surg 1987; 205: 22-6.

36. Lo HC, Wu SC, Huang HC, et al. Laparoscopic simple closure alone is adequate for low risk patients with perforated peptic ulcer. World J Surg 2011; 35: 1873-8.

37. Kok KY, Mathew VV, Yapp SK. Laparoscopic omental patch repair for perforated duodenal ulcer. Am Surg 1999; 65: 27-30.

38. Lau H. Laparoscopic repair of perforated peptic ulcer: a metaanalysis. Surg Endosc 2004; 18: 1013-21.

39. Laforgia R, Balducci G, Carbotta G, et al. Laparoscopic and open surgical treatment in gastroduodenal perforations: our experience. Surg Laparosc Endosc Percutan Techn 2017; 27: 113-5.

40. Grišin E, Mikalauskas S, Poškus T, et al. Laparoscopic pyloroplasty for perforated peptic ulcer: case report. Videosurgery Miniinv 2017; 12: 311-4.

Received: 25.03.2018, accepted: 24.05.2018. 